\section{Adult cirrhosis due to untreated congenital hypopituitarism}

\author{
Aye Nyunt MRCP Narinder Kochar MRCP \\ Daniella T Pilz MD FRCP \\ Jeremy G C Kingham MD FRCP \\ M Keston Jones MD FRCP
}

J R Soc Med 2005;98:316-317

Hypopituitarism is a diagnosis to be considered in unexplained neonatal hepatitis. ${ }^{1-3}$ Little is known about the possibility of long-term liver damage.

\section{CASE HISTORY}

A man of 25 was admitted with a chest infection. On examination he was $179 \mathrm{~cm}$ in height with eunuchoid body proportions, an infantile penis, bilateral small testes, sparse body hair and hepatosplenomegaly. Weight was $85 \mathrm{~kg}$. There was no family history of endocrine, hepatic or metabolic disease. His father's height was $184 \mathrm{~cm}$ and his mother's $168 \mathrm{~cm}$. Haemoglobin was $12.8 \mathrm{~g} / \mathrm{dL}$ and low white cell $\left(2.1 \times 10^{9} / \mathrm{L}\right)$ and platelet $\left(66 \times 10^{9} / \mathrm{L}\right)$ counts were attributed to hypersplenism. A bone marrow sample was normal. Blood tests outside the reference ranges were a low serum potassium $(3.2 \mathrm{mmol} / \mathrm{L})$ and slightly raised gamma-glutamyl transferase $(113 \mathrm{u} / \mathrm{L})$ and aspartate transaminase $(169 \mathrm{u} / \mathrm{L})$. Markers for hepatitis A, B and C infection, autoimmune liver disease, iron overload and alpha-1-antitrypsin deficiency were normal. Ultrasound examination confirmed hepatosplenomegaly, and liver biopsy showed cirrhosis with moderate chronic inflammation in the fibrous bands, mild steatosis and mild lobular hepatitis. There was a slight increase in stainable iron, no excess of dPAS positive globules and no histological indication of the cause of cirrhosis. On oesophagogastroduodenoscopy, the presence of oesophageal and gastric varices indicated portal hypertension. Endocrine investigations pointed to anterior hypopituitarism-luteinizing hormone (LH) $0.1 \mathrm{u} / \mathrm{L}$ (reference range 2-9), follicle stimulating hormone (FSH) $0.2 \mathrm{u} / \mathrm{L}(1-14)$, testosterone $<0.5 \mathrm{nmol} / \mathrm{L}(10-40$ ), free thyroxine (FT4) $5.9 \mathrm{pmol} / \mathrm{L}$ (12-26), growth hormone $<0.5 \mathrm{mu} / \mathrm{L}$, insulin-like growth

Departments of Medicine and Medical Genetics, Singleton Hospital, Swansea, UK

Correspondence to: Dr M Keston Jones, Department of Medicine, Singleton Hospital, Swansea SA2 8QA, UK

E-mail: keston.jones@swansea-tr.wales.nhs.uk factor 1 (IGF-1) $<2.0 \mathrm{nmol} / \mathrm{L}(13-50)$, cortisol $38 \mathrm{nmol} /$ $\mathrm{L}$, adrenocorticotropic hormone $(\mathrm{ACTH})<5 \mathrm{ng} / \mathrm{L}$. This was confirmed by absence of growth hormone $(<0.5 \mathrm{mu} /$ L), ACTH $(<5 \mathrm{ng} / \mathrm{L})$, cortisol $(17 \mathrm{nmol} / \mathrm{L})$ and prolactin responses to insulin-induced hypoglycaemia (glucose $1.8 \mathrm{mmol} / \mathrm{L}$ ). Raised fasting insulin and insulin concentrations after a glucose load indicated severe insulin resistance but there was no diabetes. ${ }^{4}$ The patient had a normal male karyotype. X-ray of limbs revealed open growth plates. MRI supported the diagnosis of congenital anterior hypopituitarism with an ectopic pituitary bright spot, decreased pituitary tissue in the sella and an attenuated pituitary stalk (Figure 1). Treatment was started with hydrocortisone, thyroxine and testosterone.

Born at 31 weeks' gestation after a lengthy breech delivery, the patient by day two of life had been noted to have jaundice, cyanosis, feeding difficulties and episodes of apnoea with tonic limb posturing. Jaundice increased despite phototherapy and at three weeks hepatomegaly was detected. Bilirubin peaked at $269 \mu \mathrm{mol} / \mathrm{L}$ at day six but was still raised at 15 weeks $(106 \mu \mathrm{mol} / \mathrm{L}$, of which $73 \mu \mathrm{mol} / \mathrm{L}$ was conjugated). Aspartate transaminase was $336 \mathrm{u} / \mathrm{L}$. A sweat chloride test for cystic fibrosis was normal. Liver biopsy showed cholestasis, multinucleate giant hepatocytes and foci of extramedullary haematopoiesis but no evidence of extrahepatic biliary atresia. Fasting before the procedure was uneventful. No cause was found for the neonatal hepatitis. On two occasions, during apnoeic episodes hypoglycaemia (1.9 and $1.4 \mathrm{mmol} / \mathrm{L})$ was recorded but the infant's inability to maintain a normal

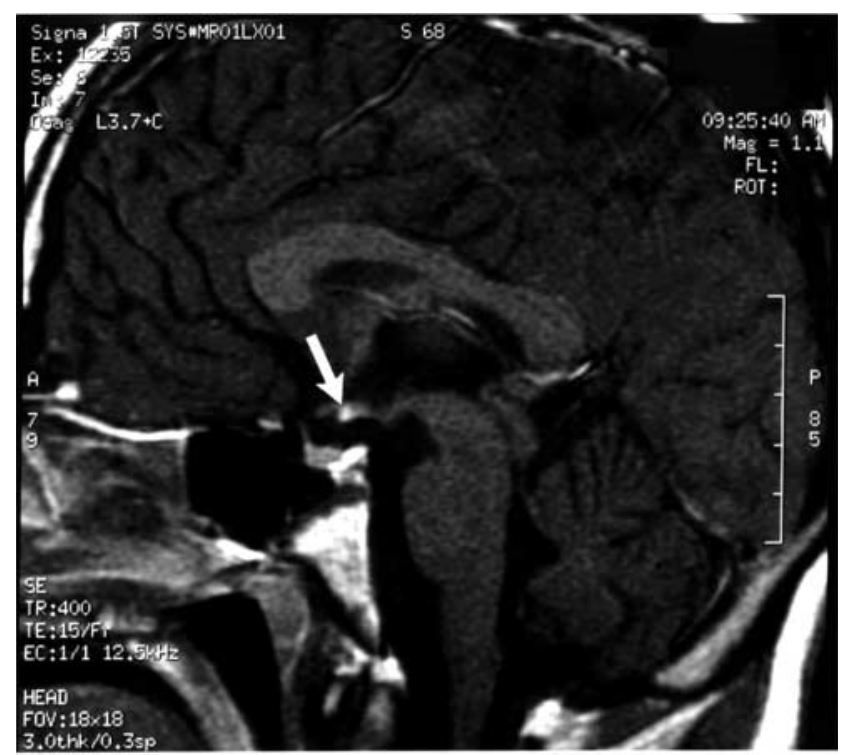

Figure 1 Post-contrast sagittal T1 weighted magnetic resonance image showing ectopic pituitary 'bright spot' in suprasellar location (arrow) with extremely attenuated pituitary stalk; anterior pituitary is hypoplastic 
blood glucose was not pursued. Microphallus was noted on one occasion but no further comment was made. On one occasion serum sodium was low $(125 \mathrm{mmol} / \mathrm{L})$; systemic bacterial infection was considered but not confirmed. Lumbar puncture yielded normal results apart from a low glucose $(1.9 \mathrm{mmol} / \mathrm{L})$. Intravenous antibiotics, dextrose, normal saline and dexamethasone were administered empirically at 15 weeks. Thereafter the infant improved rapidly with no recurrence of apnoeic spells. Liver function tests became normal by 26 weeks. At 5 years of age bilateral orchidopexy was performed for undescended testes. From then on his medical history was uneventful; the records make no comment on developmental delays and liver function was not assessed until the present admission.

\section{COMMENT}

Anterior hypopituitarism can present with recurrent hypoglycaemia, poor feeding and cholestatic jaundice. ${ }^{1-3}$ Supporting signs include micropenis, midline defects such as cleft lip or palate, and ophthalmic abnormalities associated with septo-optic dysplasia such as nystagmus or optic atrophy. Primary adrenal insufficiency may also present with hypoglycaemia and cholestasis. ${ }^{2}$ If clinical features of hypopituitarism are missed, hypoglycaemic infants may be thought to have underlying infection and given intravenous fluids and antibiotics. Frequent feeds may also mask hypoglycaemia. In the present case hypopituitarism was not recognized in early life and no cause was found for the hepatitis. Treatment with intravenous dextrose, saline and corticosteroid was followed by a remarkable recovery, with no recurrence of hypoglycaemia and gradual improvement in liver function. Investigation of the neonatal hypoglycaemia would have facilitated early diagnosis. Serum collected at the time of a hypoglycaemic episode would probably have shown low concentrations of insulin, cortisol and growth hormone. MRI is helpful for confirming hypopituitarism and excluding associated structural abnormalities. ${ }^{5}$ The hyperdense signal on T1 weighted images represents ectopic pituitary tissue resulting from migrational arrest in the fetus and non-fusion of the neurohypophysis and adenohypophysis (see Figure 1). This ectopic pituitary 'bright spot', with an attenuated stalk and reduced pituitary tissue, is typical of anterior hypopituitarism. Survival to 25 years and the height achieved in this patient suggest that pituitary hormones, in particular growth hormone and thyroxine, must have been produced at some stage in development. His normal height may also be related to delayed epiphyseal closure, severe insulin resistance and the growth-promoting effect of high insulin concentrations.

The cause of the neonatal hepatitis might be deficiency of thyroxine, cortisol or growth hormone. However, the neonatal jaundice of hypothyroidism is usually unconjugated hyperbilirubinaemia. ${ }^{3}$ There are reports of hypoglycaemia and cholestasis in infants with primary adrenal insufficiency ${ }^{2}$ but isolated ACTH deficiency has not been described in these circumstances. Certain hepatic enzymes may be growth hormone dependent, ${ }^{1}$ and work in animals points to a role for growth hormone deficiency in hepatic dysfunction; ${ }^{6}$ cholestasis and hypoglycaemia due to isolated growth hormone deficiency have not been described. Patients with isolated growth hormone deficiency or growth hormone and thyrotropin deficiency without overt hypoglycaemia generally present in later life with short stature. The precise mechanism by which endocrine deficiency causes cholestasis remains unclear.

Resolution of cholestasis has been reported with endocrine replacement therapy and occasionally without. In congenital hypopituitarism liver disease may resolve after as little as six weeks' treatment. ${ }^{3,7}$ However, in cases where hormone therapy is started late, liver disease has persisted. ${ }^{3}$ One child who remained undiagnosed until age 5 developed cirrhosis and portal hypertension and required liver transplantation. ${ }^{7}$ Nothing seems to have been reported, hitherto, on the possibility of liver damage in adult life. Hypopituitarism is a diagnosis to be considered not only in infants with unexplained hepatitis but also in young adults with unexplained cirrhosis.

\section{REFERENCES}

1 Copeland KC, Franks RC, Ramamurthy R. Neonatal hyperbilirubinaemia and hypoglycaemia in congenital hypopituitarism. Clinical Pediatr 1981;20:523-6

2 Leblanc A, Odievre M, Hadchouel M, et al. Neonatal cholestasis and hypoglycaemia: possible role of cortisol deficiency. $J$ Pediatr 1981;99:577-80

3 Sheehan AG, Martin SR, Stephure D, et al. Neonatal cholestasis, hypoglycaemia, and congenital hypopituitarism. J Pediatr Gastroenterol Nutr 1992;14:426-30

4 Wallace TM, Levy JC, Mathews DR. Use and abuse of HOMA modelling. Diabetes Care 2004;27:1489-95

5 Ultmann MC, Siegel SF, Hirsch WL, et al. Pituitary stalk and ectopic hyperintense T1 signal on magnetic resonance imaging. Am J Dis Child 1993;147:647-52

6 Bauman JW, Chang BS, Hall FR. The effects of adrenalectomy and hypophysectomy on bile flow in the rat. Acta Endocrinol 1966;52:404-8

7 Spray $\mathrm{CH}$, McKiernan P, Waldron KE, et al. Investigation and outcome of neonatal hepatitis in infants with hypopituitarism. Acta Paediatr 2000;89:951-4 